Robert H. Myers

\title{
Cooperating to Promote the Good
}

\begin{abstract}
I argue that the aim of moral activity is to cooperate with others in the promotion of value, where the concept of cooperation denotes not a formal ideal to be given content through reasoning but a substantive way of engaging with others. I show how this approach to ethical theory can provide better accounts of many of our moral convictions than consequentialist or contractualists approaches can, and defend it against the objection that, by downplaying moral reasoning, it robs itself of any explanatory force.
\end{abstract}

\section{Introduction}

The two broad approaches dominant within contemporary ethical theory, consequentialism and contractualism, struggle to make sense of the full range of our moral convictions. Opponents of consequentialism have long charged that its focus on promoting value leaves it particularly vulnerable to objections based on convictions about individual rights; opponents of contractualism have likewise charged that its focus on securing agreement leaves it especially vulnerable to objections based on convictions about impartial beneficence. Not surprisingly, some consequentialists and contractualists happily plead guilty to these charges, arguing that convictions on ethical matters are not always to be trusted, and that the correct ethical theory might very well be quite revisionary. Most consequentialists and contractualists, however, take a more conciliatory line here, insisting that their approaches can capture our convictions about rights and beneficence, perhaps not without some minor modifications, but certainly without any outright distortion.

Although I begin by rehearsing some grounds for pessimism on this score, my main aim in this paper is not to revisit this debate but to tout the advantages of a different approach to ethical theory. This approach places less emphasis than consequentialism and contractualism do on the need to understand morality's verdicts as determinations of some sort of reasoning, whether about the promoting of value or about the securing of agreement. It is more comfortable than either consequentialism or contractualism is with the possibility that morality's content might be resistant to analyses of that sort - not because it cannot be characterized in sufficiently general and informative terms, but because those terms are less formal and more substantive in nature. In some important re- 
spects, therefore, it is similar to virtue theory-although here too we shall find that the differences are also great.

The approach I have in mind regards the aim of moral activity to be one of cooperating with others in the promotion of value, where the concept of cooperation denotes not a formal ideal to be given content through reasoning but a substantive way of engaging with others. Before saying more in a positive vein about what this involves, however, let us quickly remind ourselves why some new approach seems necessary.

\section{Consequentialist Rights?}

Instead of starting with a statement of some common convictions about rights, then asking whether consequentialists can succeed in making sense of those convictions, let us start by examining the accounts consequentialists actually give of rights, then ask why people might judge them to be less than satisfactory.

The simplest way for consequentialists to try to accommodate rights is to treat them as marking facts about the impersonal value certain things possess. On views like this, to say, for example, that people have a right to free expression is to say that being free to speak one's mind is something possessing unusual impersonal value - perhaps just because it itself makes an unusual contribution to the good, perhaps also because it brings about other things that make such contributions. Whatever exactly this value consists in, however, the claim on views like this is that the amount of this value is of an order of magnitude quite different from the norm - so much so, it is said, that creating and protecting opportunities for free expression should in most cases be given priority over other things. We are in effect to think of valuable things as falling into two very broad categories, distinguished by the ease with which the value of the thing in question can be surpassed. Some things, though valuable, have a value that is easily surpassed by the aggregate value of other things, even things not themselves especially valuable. Other things, by contrast, have a value so great that it can perhaps be surpassed only by the aggregate value of similarly special things. To these things we say people have rights. ${ }^{1}$

Now it is easy to see why many people feel that views like this do not fully capture their convictions about what rights are. After all, on views like this, having a right to free expression does not guarantee that other people will not often be permitted by morality to prevent one from speaking one's mind. Admittedly, they will rarely, if ever, be permitted to do so in the name of things that do not themselves have this special value. Thus it might not be permissible to prevent the Ku Klux Klan from distributing its literature just because doing so would bring a brief moment of pleasure to untold thousands of others. However, views like this do seem to allow that one's freedom of expression might permissibly be suppressed in the name of other rights. And this is troubling to many, especially when those other rights are of the same type as one's own,

${ }^{1}$ Further distinctions might then be drawn between more and less important rights. For two examples of this approach, see Sen 1982 and Raz 1986. 
or of a type manifestly involving no greater impersonal value than one's own. The worry here is old hat. Suppose preventing some people from speaking their mind would enable a great many other people to speak theirs. This would seem to promote the overall good no matter how valuable freedom of expression is. But if a right is really at stake, shouldn't morality prohibit us from taking such steps? ${ }^{2}$

Consequentialists who hope to accommodate this conviction often try to do so by pursuing a suggestion we owe to Mill - the suggestion that rights come clearly into focus only when we look at matters from a social point of view. What should we, as a society, make of the fact that suppressing free expression would sometimes promote the overall good? One might think, at first sight, we should be trying to ensure that free expression gets suppressed in those cases, if not through the formal mechanisms involved in the law then at least through the broader mores governing public opinion. As Mill famously argued, however, collective efforts to control individual behaviour very often end up being seriously counterproductive. ${ }^{3}$ The control too often gets exercised in the wrong cases, or the costs associated with its exercise become too great. In the case of free expression, Mill of course acknowledged that certain limited attempts at collective control might prove useful. Yelling 'Fire!' in a crowded theatre really is quite dangerous, and it really can be discouraged at a small cost. But he insisted that, for the most part, we do best as a society to let people speak their minds, even though we know there will be some cases where that will end up being detrimental to the overall good. He thus concluded that we should recognize a broad right to free expression and try to protect it from violation.

Once again, however, it is easy to see why many people feel that arguments of this sort do not fully capture their convictions about what rights are. For suppose Mill's assessment of costs and benefits is no longer accurate. Suppose advances in wireless technology now enable us to implant devices in people that will accurately monitor all their communications. So now we are in a position to dissuade people from communicating in dangerous ways without having to rely either on the police and the courts, or on peer pressure and public opinion, with all their associated risks and costs. Computers can ascertain when people are communicating in dangerous ways and immediately administer painful shocks to discourage them from continuing. What could be simpler? To be sure, there will still be the problem of identifying the dangerous ways of communicating, and hence the worry that the policies governing the use of this technology might be improperly written or improperly applied. But perhaps our computers can now help here as well by sorting through the history and identifying the real dangers, thereby minimizing our reliance on possibly incompetent or corrupt bureaucracies. If so, there would seem to be every possibility that we would now do better as a society to recognize and protect only a much narrower right to

\footnotetext{
${ }^{2}$ Nozick 1974 objects in this way to so-called 'utilitarianisms' of rights.

${ }^{3}$ Mill develops this theoretical point in 1861, chap. 5. He applies it to the case of free expression in 1859 .
} 
free expression. But surely rights to free expression do not diminish just because more effective ways of suppressing free expression become available! ${ }^{4}$

Objections of this sort lead some consequentialists to adopt less restrictive views of the values that morality is concerned to promote. Since neither individual nor collective pursuit of impersonal or agent-neutral value can make satisfactory sense of common convictions about rights, they conclude that they should be looking for some way to include personal or agent-relative values in the mix. As they point out, insisting that outcomes be ranked from an exclusively impersonal point of view is not essential to consequentialism; it is simply one option, an option that should perhaps be rejected in light of the difficulties it creates for rights. Thus imagine an agent who recognizes that suppressing one person's freedom of expression will enhance freedom of expression overall. If she goes ahead, the consequences of her action will include the fact that one person's freedom of expression is suppressed, but also, of course, the fact that she herself is engaged in the suppression of a person's freedom of expression. The fact that one person's freedom is suppressed may be outweighed by the fact that other people's freedom is enhanced. But if we allow that agent-relative values are also to be promoted, there is also the other consequence to consider - we also have to consider how bad it is for her that she be the one who is doing the suppressing. If that is bad enough from her point of view, couldn't these consequentialists end up coming down against this action? ${ }^{5}$

I do not wish to quarrel here with the contention that views of this sort can fairly be described as consequentialist; but I do want to take issue with the claim that they are better able to capture common convictions about rights. What they can capture is the idea that certain actions might be problematic even though they would promote impersonal value. But why would those actions be problematic? If we follow this way of thinking, we seem saddled with an implausible answer: it would be problematic for our agent to suppress freedom of expression because doing so would be especially bad for her. Pretty clearly, this is not an answer that is going to sit very well with many advocates of individual rights. Its being especially bad for her might explain why morality would permit this agent to decline to suppress freedom of expression; but it does not seem to explain why morality would require that she decline, as advocates of rights believe it would. On the contrary, it seems to suggest that morality would applaud her willingness to proceed as a supererogatory act of sacrifice! In response, it might be argued that this agent would be acting irresponsibly if she proceeded to suppress freedom of expression, since she would be neglecting those consequences of her action that register so negatively on the scale of agentrelative value. ${ }^{6}$ But that would seem to leave us denying that morality ever permits individuals to make sacrifices that are supererogatory.

${ }^{4}$ Another worry, which I won't take time to sketch here, is that rights are commonly thought to impose restrictions on individual behaviour more directly, and not just by imposing restrictions on the law or the broader mores governing public opinion.

${ }^{5}$ For an example of someone who takes this approach, see Sen 2000.

${ }^{6}$ Sen 2000 makes much of this. 
Now at this point it might naturally be objected that there are additional agent-relative values to consider - not just the agent's, but also the victim's. Isn't it likely to be especially bad from her point of view that she be the one whose freedom of expression is suppressed in order to enhance freedom of expression overall? So if the goal is to promote agent-neutral and agent-relative value, won't that speak in favour of a prohibition against suppressing freedom of expression? But it is difficult to see how consequentialists could be justified in taking the victim's agent-relative values into account if they were not prepared to do the same for the beneficiaries. And since it is likely to be especially good from the beneficiaries' point of view that they be the ones whose freedom of expression is enhanced, it looks like the preponderance of these considerations would still come down in favour of suppression, and hence that this version of consequentialism would still not be capturing common convictions about rights. This will be particularly true if we imagine that the one person needs to be suppressed so that more other people won't need to be suppressed; for then the agent-relative values in play would be exactly the same on each side, and so it would seem that the numbers would thus be free to carry the day.

We have been painting very quickly here, and with a very broad brush; but still I think a familiar conclusion is starting to come into view - that our convictions about rights cannot be fully captured in terms of the promotion of value, not even when those values are allowed to be agent-relative as well as agentneutral. If facts about agent-relative value are to help make sense of rights, we must find a different role for them to play within ethical theory. Instead of simply introducing a different sort of good for individuals or collectives to be promoting, they must underwrite a different way of thinking about how individuals or collectives should be acting. This is of course precisely what contractualists have always argued that they do, so let us now look equally quickly at several examples of that approach. And since contractualist theories often seem to give priority to capturing common convictions about individual rights, let us focus on the question whether they can also capture common convictions about impartial beneficence. If morality includes only principles on which individuals would be reasonable to agree, where each individual is primarily concerned to promote her own agent-relative values, it would seem that advocates of impartial beneficence have a great deal of explaining to do. What reasons are there for individual agents to care about the promotion of the overall good?

\section{Contractualist Beneficence?}

Suppose some primitive group of people is in desperate need of help. We have received no help from them in the past and can foresee no occasion when we will need their help in the future. Might it not still be true that morality requires us to help?

Many will insist that morality does require us to help these people, and moreover that the amount of help we are required to give depends both on the gravity of their plight and on their numbers. To be sure, many who do insist on 
this will allow that there are limits on how much we can be required to sacrifice, as well as restrictions on the form our attempted rescue may take. Some will allow, for example, that we cannot be required by morality to put our lives in jeopardy for the sake of these people; some will say, in addition, that we cannot be permitted by morality to attempt a rescue that would jeopardize the lives of third parties. Putting these claims in the language of contemporary ethical theory, many who insist that morality imposes a requirement of impartial beneficence will allow that it is in various ways moderated and constrained by prerogatives and restrictions. But the point remains that many people are convinced that morality does impose a requirement of impartial beneficence; so the question is whether contractualist accounts of morality can offer a plausible way of capturing that conviction. Contractualists identify moral principles as those that would be agreed to by reasonable people who were seeking principles with which to govern their interactions. So the question is why we should expect reasonable people to agree that the principles governing them should include a principle of impartial beneficence.

That of course is going to depend on how the pivotal notion of reasonableness is understood, a question over which contractualists are deeply divided. At one extreme, the Hobbesians, as we might call them, will stipulate that reasonable people would seek principles as advantageous to themselves as possible. This makes it especially hard to account for convictions about impartial beneficence, as it is far from clear why comparatively privileged people like us would find such a potentially burdensome principle to be to their advantage. Even if it were moderated and constrained by various prerogatives and restrictions, there is no straightforward way in which we would stand to gain from a principle requiring that we help people who cannot help us. In response, it might be argued that such a principle would at least insure us against the possibility of someday becoming marginalized ourselves. But since our circumstances really are quite privileged, we must ask whether the expected costs of this insurance would be worth the expected benefits. To be sure, even if we do not agree that this insurance would be directly worth our while, other people may, and they may refuse to cooperate with us if we refuse to share its costs. But then we must ask how much we need the help of people who are so precariously situated, and whether we would not do better to restrict our cooperative circle to those who are better off.

The question, therefore, is why reasonable people should be expected to accept a principle of impartial beneficence even when they could secure a better deal. If contractualists are going to answer this question, they are clearly going to have to redefine reasonableness so it involves real sensitivity to other people's claims. Some contractualists - we might refer to them as Lockeans - attempt to do this by stipulating that reasonable people would refuse to accept a set of principles if its acceptance would not be advantageous to everyone concerned. ${ }^{7}$ They hope that, by redefining reasonableness in this manner, principles of impartial

${ }^{7}$ Locke himself was not a thoroughgoing contractualist; so this terminology is perhaps not ideal. But I think it does help us isolate a familiar and important strand of contractualist thought. 
beneficence will come to seem reasonable, since any set of principles omitting impartial beneficence would threaten to leave some people in need of help. The trouble, however, is that a set of principles can threaten to leave some people in need of help yet still be advantageous to them. Imagine a set of principles requiring us to provide assistance to some token number of those in need but permitting us to ignore all the rest. Since this set of principles would give each person in the endangered population some chance of receiving assistance, there is an obvious sense in which they should view it as better than nothing and so advantageous. But this is clearly a long way from the principle of impartial beneficence that many people hold dear, as the amount of assistance it calls for would not depend on the amount of good at stake.

It is of course easy to imagine different sets of principles that the needy would find more advantageous. There is evidently a spectrum of possibilities requiring us to help increasingly large numbers within the endangered population. So it might quite plausibly be objected that the possibility we just imagined was not really mutually advantageous, since it pretty clearly did not give the claims of the needy a weight comparable to our own. The trouble with this, however, is that it is far from clear what it would be in this context to give everybody's claims comparable weight. David Gauthier has suggested that it would be to minimize the maximum concession anyone has to make from the set of principles most advantageous to them (Gauthier 1985, ch. 5). But it might be wondered whether this idea actually has determinate content. We might be best served by a set of principles that did not require us to help any of the people in our example. They might be best served by a set of principles requiring us to help every one of them as much as we possibly can. Any compromise will impose relative costs both on them and on us. It might seem easy enough, therefore, to identify the point at which the greatest costs to be borne are as small as they can be. But that assumes we can agree on the measure of one another's costs - and that may prove not to be such an easy matter after all.

For our purposes here, however, a simpler objection to the Lockeans is probably more telling. For even if they ultimately can give sufficiently determinate content to their idea of mutual advantage, principles of impartial beneficence do not seem very likely to win their blessing in the end. Certainly Gauthier gives no indication that he believes his arguments would justify principles of that sort. As long as the focus is on finding a set of principles that would be adequately advantageous to everyone, it seems pretty clear that principles of impartial beneficence will deserve attention only as part of an opening bid-as part of the package of principles that would be ideal from the point of view of the needy, but from which they are going to have to retreat if a mutually advantageous compromise is to be secured. It should come as no surprise, therefore, that contractualists who seek to accommodate principles of impartial beneficence typically insist on putting even greater distance between the notions of reasonableness and advantage. For example, when introducing his version of contractualism, T. M. Scanlon makes a point of insisting that it can be unreasonable for people to reject principles from which they stand to lose (Scanlon 1998, ch. 5). As he puts it, it would be unreasonable for someone to reject a set of principles if the sacrifices it would 
require from her would be smaller than the sacrifices alternative sets of principles would require from others. At first sight, this suggestion might still seem of a piece with Gauthier's criterion of minimizing maximum relative concession; upon closer inspection, however, the differences separating these two conceptions of reasonableness turn out to be quite significant.

Instead of comparing the relative impact that different sets of principles would actually have on different groups of people, Scanlon suggests that we compare the different 'generic reasons' that different 'representative individuals' could offer for the contending positions. In the case we are imagining, for instance, we should compare a typical privileged person's reasons not to want to sacrifice her surplus resources with a typical needy person's reasons not to want to lose her very life. As Scanlon sees things, reasonable people would find it clear that the resources that stand to be lost in this case are less important than the lives that stand to be gained. ${ }^{8}$ He concludes, therefore, that we don't have to compare the individually reckoned costs and benefits in order to see that it would be unreasonable to reject a principle of impartial beneficence. A principle of impartial beneficence does not figure simply as an opening bid on the part of the needy, from which they will inevitably have to retreat in the search for principles that minimize maximum relative concession. We can also ask what reasons the needy have to favour the adoption of a principle of impartial beneficence, and weigh them against the reasons the privileged have for preferring the adoption of some weaker principle of assistance. When we do this, Scanlon thinks, we find that the case for impartial beneficence is strong, for people have weighty reasons to want their urgent needs to be taken seriously by others. Those others may themselves have reasons weighty enough to make the case for prerogatives and restrictions, but they do not have reasons weighty enough to keep impartial beneficence out of the mix.

I think Scanlon is right in holding that this line of argument makes the case for impartial beneficence; my worry, however, is that it does so only by undermining the case for prerogatives and restrictions. For example, consider a restriction that would prohibit us from suppressing one group's freedom to speak their mind even though that was necessary to prevent a larger group's freedom to speak their mind from being suppressed. On the one side, it would seem that a representative member of the smaller group would have strong generic reasons to favour this restriction, since being treated in this manner would be extremely damaging and unfair. By the same token, however, a representative member of the larger group would seem to have the same generic reasons to reject it, since members of that group are being threatened with the same treatment. ${ }^{9}$ And since Scanlon needs to allow the numbers to decide other cases where contending generic reasons cancel out, it is difficult to see how he could avoid allowing the numbers to decide this case as well. Thus imagine a case in which two

\footnotetext{
${ }^{8}$ As Scanlon acknowledges, in weighing these generic reasons we are making moral judgements of a sort. But since these are not judgements about wrongness, they do not introduce a threat of circularity.

${ }^{9}$ To ensure that the threat is the same, we might imagine that their freedom is also being suppressed in order to prevent a still larger group's freedom of expression from being suppressed.
} 
misinformed consequentialists have each independently arrived at the mistaken conclusion that they could promote freedom of expression for the many only by suppressing freedom of expression for a few. And suppose the one believes she could do this by preventing only five people from speaking their minds, while the other is convinced it would actually require her to prevent ten people from speaking their minds. Clearly, if we cannot stop both of them, morality requires us to save the ten, not the five. But can Scanlon allow the numbers to decide this case, without also allowing them to decide the other?

As always, there is more that could be said about these cases. However, I do think what we have said is enough to suggest that Scanlon's version of contractualism might encounter difficulties on this front. Moreover, I don't think these difficulties should come as any surprise. After all, we have already concluded that it is difficult to make good sense of common convictions about rights when reasoning about promoting value. So, to the extent that reasoning about securing agreement turns out to support a principle of impartial beneficence, it is only to be expected that it will inherit many of the worries that plague consequentialist theories. Indeed, some might wonder at this point whether we shouldn't be exploring the possibility of a bifurcated theory, a theory invoking contractualist reasoning to account for individual rights and consequentialist reasoning to account for impartial beneficence. ${ }^{10}$ I don't see how that could work, however, since the moral realm isn't divided in that way. The needy aren't just a group we should help; they are also individuals with rights we should respect. Even if violating the rights of some of them would enable us to help more of them overall, that is probably not something we should be doing. How is our theory to account for such facts? Either it needs to lay out a new form of moral reasoning that combines contractualist and consequentialist elements, or it needs to explain how such facts can be justified without invoking moral reasoning of any sort. As I mentioned at the outset of this paper, it is the second of these two options that I think ethical theorists should be taking more seriously. So let us now turn our attention to it.

\section{An Alternative Approach}

The idea I want to explore is that acting morally is a substantive way of engaging with other people in the promotion of value. To act morally, I suggest, is to cooperate in promoting the good. So of course the question is what participating in this endeavour involves.

Consequentialists and contractualists are likely to respond to this suggestion by insisting that this is in effect what they have been discussing all along. Consequentialists are likely to insist that people cooperate in the promotion of value only by seeking its maximization, if not as individual agents then at least as members of some larger group. Similarly, contractualists are likely to insist that their focus on reasonable agreement is just another way of insisting that people cooperate with one another. It seems to me, however, that we have views

10 Mulgan 2001 develops a view along these lines. 
about what it is to cooperate that are independent of, and sometimes incompatible with, these consequentialist and contractualist ways of analyzing things. People can be cooperating in the promotion of some end even if they are not always doing everything they can to promote that end. On the contrary, doing everything they can to promote that end could occasionally be downright uncooperative, though not necessarily because they would be violating principles to which reasonable people would all agree. To cooperate with others in some endeavour just is to engage with them in a manner that is structured by such prerogatives and restrictions. This is not something we have to learn through reasoning about promoting value or securing agreement; it is something we immediately appreciate in coming to understand what sort of activity cooperating is.

Suppose you and I are working on a book together, and I notice that you are capable of writing more effectively than I am. Hoping to make our book a better one, and knowing of your love for your daughter, I therefore threaten her with harm unless you agree to do the rest of the writing. My action may very well result in a better book, but it would be absurd to say that I have cooperated in this endeavour. It would be no less absurd to say that you were not cooperating in this endeavour, just because you were unwilling to take on the full burden of the writing by yourself. To describe the two of us as cooperating in this endeavour suggests that each of us is contributing a fair share of the work. Perhaps you could voluntarily take on more than your share without failing to cooperate with the me, provided you did so in a way that left me the option of doing my part. But if I force you to do more I am failing to cooperate with you, even if my intention is to improve our book. My claim is that cooperative undertakings must be structured in this manner by prerogatives and restrictions, and that this is something we know to be true independently of consequentialist or contractualist reasoning. ${ }^{11}$

Now it might be objected that contractualist reasoning is clearly still at work here, and that all this example shows is that people who are writing a book together would be reasonable to agree that certain prerogatives and restrictions should be governing their interactions. But the question is why it would be reasonable for these people to agree on this. If the objection is to have force, the answer can't be that it would be reasonable for them to agree on this because this is what cooperating involves! It must be that recognizing certain prerogatives and restrictions would be mutually advantageous to these people, or would strike a reasonable balance among the various generic reasons that each of them has. But if you really are capable of writing much more effectively than I am, and if I would be content making only minimal contributions to the writing myself, it might be very much to my advantage that we not recognize any fixed limits

11 When I first broached the idea that acting morally is a matter of cooperating with others in the promotion of value, in Myers 1994 and 1999a, I was still thinking that it would be through something like contractualist reasoning that we would identify fair terms of cooperation. I now think that that was a mistake. While contractualist reasoning will very often be relevant to the question of what our particular obligations in concrete cases are, I now think that we understand the broad contours of our obligations simply by appreciating what cooperating with others involves. 
on how much each of us may be required to contribute to the writing of our book. Thus the argument is probably going to have to rest on the claim that your generic reasons to favour such limits outweigh my generic reasons to oppose them. But the difficulty is going to be to determine how those reasons should in turn be weighed against the generic reasons we have to write our book together in the first place.

The example of writing a book together may at this point prove somewhat misleading, for it may be that our reasons for writing the book aren't that important, in which case contractualist reasoning of this Scanlonian sort would indeed generate the conclusions we seek, perhaps suggesting that the case for prerogatives and restrictions always depends on reasoning of this sort. But now, if we are cooperating, not just in the writing of a book, but actually in the promotion of the good, matters are likely to be different. If it is again true that you are capable of contributing more effectively than I am, I am again going to have generic reasons to oppose any fixed limits on how much each of us may be required to contribute to the promotion of the good. No doubt your generic reasons to favour such limits will again be much stronger. But will they be strong enough to outweigh our generic reasons for promoting the good together? That is less obvious, and yet it is still obvious that such limits should be recognized. No matter how important our reasons for promoting the good are held to be, cooperating does not require that you always do everything you can to promote it. Nor does it permit me to promote the good by forcing your hand in this respect, even if that would in fact produce more good than anything else that I could do. ${ }^{12}$

The truth of such claims is probably easiest to appreciate in cases of partial compliance. If I fail to do my part to promote the good, there may be that much more good for you to do. But it doesn't necessarily follow that you will be failing to cooperate if you don't take up the slack for me. That will depend on many things - on why I failed to do my part, on how much more good there now is for you to do, on how much doing this extra good would cost you, and so forth. Clearly there will be some cases where cooperating actually would require you to take up the slack for me. If cooperating originally required each of us to save one of two drowning children, yet I fail to help because I exaggerate the risks to me, then it may well now require you to take up the slack, especially if saving the second child would not be a great hardship for you or put you at great risk. ${ }^{13}$ The point is simply that there are bound to be other cases where this isn't so. If I just can't be bothered to do my part, and taking up the slack

12 Since Scanlon allows that considerations of fairness can ground generic reasons, it might be thought that he must be able to replicate this result. For couldn't you complain that my forcing you to contribute more than your share to the promotion of the good would be terribly unfair? But, again, what if I had to treat you unfairly in order to prevent a greater number of other people from being treated unfairly? So long as we are simply comparing complaints, as Scanlonian contractualism does, it seems inevitable that the numbers are going to decide such cases. This is why I believe it is so important for us to construe morality instead as a substantive way of engaging with one another. Scanlon occasionally talks as if he is doing this himself, but I think his continued reliance on contractualist reasoning shows that he's really not.

${ }^{13}$ For a different take on examples of this sort, see Murphy 1993. 
would cost you a lot, then there is a good chance you will still be cooperating even if you refuse to do more than your original share.

How are people's original shares to be allocated, if not via consequentialist or contractualist reasoning? This again is going to depend on a great many things, but foremost among them will be the demands on the agent. In some cases, each person would be required to contribute as necessary to maximize the amount of good that gets generated. ${ }^{14}$ Clearly, however, there are other cases where such 'full coordination' shares would be problematic. No one is required to become a slave to the good, even if that is what full coordination would demand of them. The difficult question is therefore to determine when and how people's 'full compliance' shares differ from these full coordination shares. There just doesn't seem to be any one answer that holds for all cases. For example, in many cases, full compliance would not require people to pursue the specific careers that full coordination would require them to pursue. But if enough was at stake, and someone had little invested in the choice, that may not be too demanding. It might not be a good idea for other people to force this person to pursue that career, given all the ways that could go wrong. But still, depending on the case, it might be right to say that this person would not be cooperating in the promotion of the good if she did not make that choice.

What I am proposing, therefore, is something akin to a virtue theory -albeit a virtue theory that gives one virtue primacy over all the others. Like a virtue theory, the account that I am proposing plays down the role that calculative reasoning enjoys in the justification of moral judgements and plays up the role of holistic appreciation. The ideal judge of moral matters must be appropriately sensitive to the myriad ways in which factors can become relevant to judgements of right and wrong. Unlike most virtue theories, however, the account that I am proposing takes a particular view of the general shape of the considerations to which the ideal judge must be appropriately sensitive. It doesn't just say that the right thing to do in a situation is whatever the person of practical wisdom would advise in that situation, or whatever would be favoured by the totality of the factors relevant in the situation; it insists from the beginning on the primacy of cooperating in the promotion of the good. Considerations of other sorts may come to the fore in other contexts - for example, when deciding what is required of good friends or of good parents. ${ }^{15}$ But the suggestion is that, when we are deciding what is required of fully moral agents, our focus should be on what is involved in cooperating in the promotion of the good.

Now some consequentialists and contractualists will object to this suggestion on metaethical grounds. And indeed, if there were no agent-relative reasons, as some consequentialists believe, one might expect that morality would require people not merely to cooperate in the promotion of the good but actually to seek its maximization, if not as individuals, then in larger groups. Or again, if there

14 And thus some may be required to contribute more than others. I am not assuming that full compliance shares will always be equal.

15 Even here, though, one would think that a good friend or a good parent should also be capable of being a good moral agent. So, in working out what is required of them, we cannot completely lose sight of what cooperating in the promotion of the good requires. 
were no agent-neutral reasons, as many contractualists believe, one might expect that morality would require people not actually to cooperate in the promotion of the good but merely to act in ways that are acceptable to everyone, if not in the Hobbesian sense then in one of the other senses we distinguished earlier. The suggestion that morality requires people to cooperate in the promotion of the good will seem unmotivated unless reasons of both sorts are assumed to exist. In another context, therefore, we might want to consider whether that assumption really is justified. ${ }^{16}$ In this context, however, I think we may be forgiven for taking it as read. Our brief was to provide an account of morality's content that can successfully accommodate both common convictions about individual rights and common convictions about impartial beneficence, not to do this on the assumption that all reasons for action are of one kind. So let us finish by considering some worries about whether this brief has actually been met.

\section{Problems and Prospects}

The worry I shall focus on here is that our understanding of cooperation is not sufficiently independent of our convictions about prerogatives and restrictions, and that construing morality as a cooperative undertaking therefore presupposes that it includes prerogatives and restrictions rather than explaining why it does so.

One way to respond to this worry is to think briefly about the differences between what I have elsewhere called self-governance and cooperation (Myers $1999 ; 1999 \mathrm{a})$. On the assumption that agent-relative and agent-neutral reasons both exist, it is natural to suppose that a self-governed person should be aiming to strike the correct balance between whatever agent-relative reasons she happens to have and whatever agent-neutral reasons there happen to be. So, if people have agent-relative reasons to pay special attention to the needs of their friends, then I should aim to do that; and if there are agent-neutral reasons to give some consideration to the needs of any person, I should also aim to do that. Self-governance requires me to respond appropriately to both sets of reasons, to give my friends some priority but not more than they deserve. But what does self-governance require me to make of your agent-relative reasons to pay special attention to the needs of your friends? Arguably, it requires me to take no account of them at all. Of course, there may be agent-neutral reasons to give some consideration to the needs of any friendship, in which case self-governance would require me to give some weight to the needs of your friendships - which might in turn require that I give some consideration to the ways in which I could help you give priority to your friends. But this would not require me to give your agent-relative reasons any direct bearing on the question of what I should be doing. It would require me generally to promote people's privileging of their friends, whereas your agent-relative reasons require your friends to be particularly privileged.

${ }^{16}$ I rebut some arguments against this assumption in Myers 1999a, chap. 3. 
Cooperation, by contrast, does require me to give your agent-relative reasons some direct bearing on the question of what I should be doing. More than that, it requires me to take your agent-relative reasons into account in a way that is fair to both of us. Suppose a consequentialist were to suggest that one thing I should be seeking to promote is the satisfaction of agent-relative reasons quite generally, while a contractualist were to suggest that I should be abiding by principles that any person would have good agent-relative reasons to accept. It seems to me that both of these suggestions could be rejected on the grounds that they don't take fair account of the fact that other people have agent-relative reasons in addition to the agent-neutral reasons everyone shares and that cooperators must be sensitive to this. The consequentialist's suggestion, by treating the satisfaction of your agent-relative reasons as just another value to be promoted alongside all the others, does not take fair account of the fact that self-governance requires you to give a different weight to those same agent-relative reasons. It treats agent-relative reasons as another source of agent-neutral reasons, not as independent reasons especially important to those whose reasons they are. The contractualist's suggestion avoids this objection by granting your agent-relative reasons an effective veto over the principles that are to govern our interactions; but by granting the same veto to every person's agent-relative reasons, it risks treating you and your reasons unfairly in a different way. For if other people's capacities and circumstances are sufficiently different from yours, they might have reason to give you and your reasons short shrift. ${ }^{17}$

So how do we take fair account of the fact that other people have agentrelative reasons in addition to the agent-neutral reasons everyone shares? Pretty clearly, we acknowledge that people have the prerogative to give some priority to their own agent-relative reasons, and thus the prerogative not always to contribute everything they can to the promotion of the good. And we give teeth to this prerogative by also acknowledging that it places people under a restriction not to force one another to make supererogatory contributions. Indeed, some such arrangement of appropriately coordinated prerogatives and restrictions seems so obviously to be what cooperation requires that one can sympathize with objectors who worry that our explanans is too close to our explanadum. As we have just seen, however, it is possible to criticize consequentialist and contractualist accounts of cooperation without mentioning their troubles with prerogatives and restrictions. We can look in a general way at the manner in which they would have us take account of the fact that other people have agentrelative reasons to act and find that it is unfair. So even if its connection to prerogatives and restrictions really is very close, I don't think this prevents the idea of cooperation from doing explanatory work. If nothing else, it reminds us that morality requires people to take fair account of one another's agent-relative reasons, even if this means on some occasions that they can't take full account of their own. ${ }^{18}$

17 This wouldn't happen on Scanlon's version of contractualism. The worry in his case is that the numbers will end up deciding trade-off cases.

18 For some discussion of what this implies for the authority of moral reasons, see Myers 1999. 
In the long run, however, the best way to quiet worries about the explanatory force of the idea of cooperation will be to show how, by invoking the idea that acting morally is a matter of cooperating in the promotion of the good, we can explain other facets of morality in addition to the fact that it includes both prerogatives and restrictions. It's a bit late in the day to be doing that here, of course, but I think there are real grounds for optimism on this score. Consider, as one example, the case of promissory obligations. That morality includes such obligations is hardly in dispute; but this again is something that is not easy to account for within either consequentialist or contractualist theories. Consequentialists tend to emphasize the good that comes of the practice of promising, arguing that promissory obligations are rooted in the need to support that practice. As is often noted, however, this leaves them vulnerable to counterexamples suggesting that promissory obligations can exist even if the practice is not at risk or there is no practice in place to begin with. ${ }^{19}$ Contractualists of course look to the reasons individuals have to accept promissory obligations, often stressing the interest people have in being able to rely on one another. But again the worries are familiar. Are promissory obligations the only or the best means by which to gain this ability? Can we be sure that this is an ability everyone has an interest in gaining?

Given how much more powerful some people are than others, it is far from obvious that any principle requiring general fidelity to promises would pass the test of mutual advantage. It may not happen very often that the powerful have an interest in what the powerless will do, and they may have ways of getting them to do things that are more effective than trading promises. Once again, therefore, it would seem that the contractualists' best bet is probably to follow Scanlon and focus not on mutual advantage but on representative individuals and generic reasons. But it is not immediately clear how this would help with the worry that trading promises might not always be the most effective way to ensure that people will do what one wants them to do. It may be, as David Owens has recently argued, that Scanlon himself would do better to construe promises as serving not people's interests in assurance but their interests in authority - that is to say, not their interest in being assured that others will do what they'd like them to do, but their interest in having the authority - the moral authority - to require those actions of them (Owens 2006). But then the question would be whether the powerful don't have important generic reasons to reject any principle that would put their moral authority over their own actions at risk. And given the value contractualists attach to individual autonomy, this may be hard for them to rule out-leaving their case for the existence of promissory obligations much weaker than it is commonly held to be.

Now contrast this with the explanation of promissory obligations that can be offered if we construe morality as a matter of cooperating with others in the promotion of the good. To cooperate with others in this endeavour is not simply to adjust one's efforts in light of theirs; it is in some sense and in some measure to work as one with them towards this end. But how are people to do this,

19 It also makes it hard for consequentialists to explain why promissory obligations are owed to promisees, and not to all participants in the practice. 
especially given our earlier conclusion that cooperators are often permitted to contribute less than they possibly could to the promotion of the good? It is difficult to see how they could act as one towards this end if they were unable to transfer this authority to others so as to decide as one what course of action to take. Whether or not people always have the general authority interests to which Owens links promises, it is clear that cooperators always have such interests when it comes to their fellows. Cooperation wouldn't be possible if people couldn't promise to perform actions of various designated sorts if and when actions of those designated sorts were deemed desirable by whoever was charged with making the decision in question. On the cooperative view of morality, therefore, the case for promissory obligations looks strong. Trading promises with people is just part of what it is to cooperate with them. Promissory obligations are not merely instrumental. Nor are they dependent upon the reasonable agreement of possibly uninterested individuals. They are a constitutive part of the way of engaging with other people that is definitive of morality.

A similar, though no doubt ultimately more complicated, explanation might be offered of obligations to obey the law. Here again, consequentialists tend to stress the good produced by legal systems and the importance of acting in ways that will not undermine them, whereas contractualists look for individual interests that every person can be expected to have and that obeying the law can be expected to serve. Thus both approaches threaten to make the connection between law and morality more contingent than many would like. Given how difficult it would be for large groups of people to cooperate in the promotion of the good without recourse to the law, our cooperative conception of morality promises to do better on this score - though not so well as to invite attacks on the other flank. As I have acknowledged, the argument here will without doubt be more complicated than the argument regarding promises. Questions about what, exactly, the law is will clearly be more difficult to answer than questions about what, if anything, a person has promised, as will questions about the conditions on our obligations to obey the law, whatever it is (for of course there will be some conditions). More importantly in the context here, the law is probably not as integral to cooperating as promising is. ${ }^{20}$ But still, these important differences notwithstanding, one might hope that a fuller account of what cooperating in the promotion of the good involves would demonstrate the connection between law and morality to be closer and more secure than most consequentialists and contractualists seem capable of allowing.

These are of course merely gestures towards explanations of our obligations to honour promises and obey the law. My claim here is simply that our understanding of what cooperation involves is strong enough and rich enough to underwrite explanations of this sort, and that we should thus not be unduly troubled by the worry that appeals to the concept of cooperation presuppose more than they explain. On the contrary, we should be motivated to think that much harder about what else cooperating might involve. Considered individually, each explanation of this sort may seem vulnerable to the worry that it

${ }^{20}$ For example, it is at the very least a contested question whether cooperation among nations requires international law, or whether promissory obligations will suffice. 
is in fact presupposing more than it is explaining; together, however, they will establish that the general concept of cooperation is adequately independent, and therefore potentially explanatory, of its particular features. So long as we are just analyzing the concept, the explanations we uncover will undoubtedly be quite schematic. Thus I think we can explain why people necessarily have some obligation to respect prerogatives, abide by restrictions, honour promises and obey the law, but I don't see any prospect of providing a way by which to calculate what particular obligations people will be under in concrete cases. There I see no alternative but to rely on holistic appreciation of all the many factors in play. Some consequentialist and contractualists might see this as an admission of failure, and hence as good reason for them to stick to their guns. But given how long they have been firing blanks, it seems wiser to conclude that a different approach to ethical theory is called for.

\section{Bibliography}

Gauthier, D. (1986), Morals by Agreement, Oxford

Nozick, R. (1974), Anarchy, State, and Utopia, New York

Mill, J. S. (1859), On Liberty

- (1861), Utilitarianism

Mulgan, T. (2001), The Demands of Consequentialism, Oxford

Murphy, L. (1993), The Demands of Beneficence, in: Philosophy and Public Affairs 22, 267-292

Myers, R. (1994), Prerogatives and Restrictions from the Cooperative Point of View, in: Ethics 105, 128-152

- (1999), The Inescapability of Moral Reasons, in: Philosophy and Phenomenological Research 59, 281-307

- (1999a), Self-Governance and Cooperation, Oxford

Owens, D. (2006), A Simple Theory of Promising, in: Philosophical Review 115, 51-77

Raz, J. (1986), The Morality of Freedom, Oxford

Scanlon, T. M. (1998), What We Owe to Each Other, Cambridge/MA

Sen, A. (1982), Rights and Agency, in: Philosophy and Public Affairs 11, 3-39

- (2000), Consequential Evaluation and Practical Reason, in: Journal of Philosophy $97,477-502$ 
